\title{
A CASE-BASED STUDY OF LEAN CULTURE AMONG SOUTH AFRICAN CONTRACTORS
}

\author{
Fidelis Emuze ${ }^{1}$ and Willem Mpembe ${ }^{2}$
}

\begin{abstract}
Problems such as low productivity, poor health and safety, poor working conditions, waste and insufficient quality, and poor performance are experienced in the South African construction industry. The call for change is necessary as South African construction is constrained by a lack of required skills and under-performing employees and management, which collectively generate waste on projects. However, lean construction (LC) concepts, tools and techniques could be used to resolve such problems that exist in South African construction.

Thus, the study reported in this paper was undertaken to investigate how contractors could help to drive the implementation of lean construction in South Africa. A multi-casestudy research design was used to discover how contractors could address implementation problems by adopting a lean culture. The results from the study, obtained through crosscase analysis, showed that the contractors perceived that LC cannot be implemented so there is significant scope for tackling resistance to change through engaged LC education and training.
\end{abstract}

\section{KEYWORDS}

Contractors, culture, leadership, lean construction, people.

\section{INTRODUCTION}

Lean construction (LC), which is the application of lean thinking to the design and delivery of projects (Tommelein \& Ballard, 2016), has been practised in other countries in recent years but has not been adopted fully in the construction industry in South Africa. LC is understood to be a new project management philosophy which differs from traditional project management in the ways in which goals are pursued, phases are structured, and the ways in which the phases and the participants within each phase are related (Ballard \& Howell 2003). LC is not only a way to reform how work on projects is performed, but also a way to design production systems to minimise waste of materials, time, and effort in order to generate the maximum possible amount of value (Forbes \& Ahmed 2020).

According to Emuze and Ungerer (2014), change is necessary in South African construction that is constrained by a lack of appropriate skills, motivation and leadership, and under-performing employees, which fuel the wastes encountered in the sector. Various chronic problems, such as low productivity, poor safety, inferior working

1 Professor, and Head, Department of Built Environment, Central University of Technology, Free State, Bloemfontein, South Africa, femuze@ cut.ac.za, orcid.org/0000-0001-7714-4457

2 Postgraduate Diploma Graduate, Department of Built Environment, Central University of Technology, Free State, Bloemfontein, South Africa, mpembewillem@gmail.com, orcid.org/0000-0002-8804-8206 
conditions, waste and defects are experienced in South African construction, similar to other countries around the world (van Rooyen 2010). However, other countries (especially developed countries in North America and Europe) have embraced LC to solve some of these common problems. AL-Najem et al. (2012) noted that there is growing concern in the corporate world about the implementation of lean practices in large organisations and small- and medium-sized enterprises (SMEs). One of the reasons for this is a lack of understanding of culture, and the critical issues of lean implementation are related to organisational culture (AL-Najem et al. 2012).

The need for change in South African construction is evident from the number of performance-related issues that have appeared in media headlines relating to fatalities and overruns of project time, amongst others (Emuze \& Ungerer 2014). Contractors should consider the implementation of lean practices to improve project and business outcomes. However, the efforts of contractors will fail to have an effect if organisational cultural barriers, militating against successful implementation, are not identified and understood. In effect, knowing the cultural barriers of an organisation helps to achieve successful implementation of LC to obtain optimal results (Sarhan \& Fox 2013).

The central research question of this study was how contractors could help to drive the implementation of lean construction in South Africa. Although management problems facing contractors, and the leadership attributes that affect how contractors think and act lean were also examined in the study, in this paper, the data on how managing organisational culture could help contractors to engender lean practices in their enterprises have been presented.

\section{OVERVIEW OF HOW CULTURE AIDS LEAN PRACTICES}

Lean principles relate mainly to reducing waste in either project or organisational processes. Thus, establishing an organisational culture with a waste elimination mind-set promotes the lean philosophy (Puvanasvaran et al. 2015). According to Scoggin (2017), it has been reported that cultures not only affect the psychological process of individuals, but also the sociological, political, and economic functioning of organisations. Culture is a key factor in successful implementation of lean principles, for it determines the acceptance or rejection of ideas or processes and, ultimately, whether an organisation can be sustained in a competitive environment (Pakdil \& Leonard 2015). Contractors are involved directly in the process of implementation and, therefore, have an understanding of organisational culture, its impact on performance, and its effects on employees' behaviour. Puvanasvaran et al. (2015) mention that it is necessary also to change the organisational structure to make it more flexible, and continue by arguing that flexibility enables the redeployment of organisational resources to satisfy customers' needs. To avoid employees' resistance to change, it is critical to involve all employees in the adoption of the principles from the start.

Organisational culture has an impact on performance since it affects behaviour, and also it is a key factor in the success of lean processes because culture determines whether an idea or process is accepted or resisted (Santorella 2017). Organisational culture also provides employees with an organisational identity, which normally begins with a leader who articulates and implements particular ideas and values in the form of an organisational vision. Implementation of lean practices requires significant investments by the organisation, including time and money but, if employees return to previous behaviour, the improvement cannot be sustained over time and fails. An effective, lean manufacturing transformation requires an organisation to identify and address the culture 
within its working environment (Ahmad 2013; Fadnavis et al. 2020). Fadnavis et al. (2020) showed that there is a positive correlation between organisational culture and the ability of team members to engage in structured problem-solving practices for continuous improvement. Thus, leaders need to possess an understanding of the various types of organisational cultures in order to create and align the organisational structure effectively to the desired lean system.

Leadership, communication, empowerment and teamwork are elements of lean culture that are essential to improvement (Rubrich 2012). These four elements will help contractors to develop guiding principles or behavioural expectations. Sarhan and Fox (2013) show that although there seems to be positive trends in the development of a lean culture amongst UK contractors, but there is a major lack of understanding of how to successfully apply lean to specific construction processes and activities. According to Sarhan and Fox (2013 p.3), the construction industry is known to be opportunistic, prone to conflict and resistant to change. Therefore, changing traditions and behaviour is a necessary prerequisite for implementing LC in South Africa. Several authors have discovered that structural patterns in resistance to change, apathy towards, or limited, training, and lack of contractor engagement hinder the implementation of lean practices in organisations (Rooke 2020).

Having explored how LC should be implemented by contractors in South Africa, van Rooyen (2010) contended that construction companies need to learn how to manage in an environment of rapid change and uncertainty, and LC offers concepts and tools to assist them. Nine years after the study by van Rooyen (2010), it is still unclear whether such learning is taking place within construction organisations in South Africa.

\section{RESEARCH METHOD}

The scope of this study involved three building projects in Bloemfontein, South Africa. The three cases were on-going, commercial construction projects at the time of data collection in 2019. A case-study research strategy was used for the study as it promotes in-depth inquiries (Yin 2013). The data were collected by conducting semi-structured interviews, supported with a demographic questionnaire.

Creswell (2013) emphasised that, when dealing with case studies, a researcher must select a sampling strategy that represents multiple perspectives in order to build sound empirical evidence. According to Yin (2013), the sampling strategy determines the depth of the accumulated empirical detail. For this reason, the sample was selected according to the purposive convention, as explained by Yin (2013).

The three projects were selected purposively, based on the experience of the main contractors in terms of managing projects. The same criteria (experience and exposure) were followed in selecting the consulting professionals who were interviewed. The interviewees included contract managers, site agents, a site engineer, construction project managers, foremen, supervisors, quantity surveyors, artisans, and general workers and their respective assistants, as shown in Table 1. The consulting engineer's team had been appointed to advise the projects in all three cases, which was why they were considered as being part of managing the projects. The client and sub-contractors did not form part of the interviews because they did not form part of running or managing the projects. 
Table 1: Demographic Data

\begin{tabular}{cllc}
\hline Case & \multicolumn{1}{c}{ Construction Team } & \multicolumn{1}{c}{ Consulting Team } & No. \\
\hline Case Project 1: & 1 Site manager & 2 Project managers & $\mathbf{9}$ \\
(Retail Organisation) & 3 Foremen & & \\
& 1 Jnr Foreman & & \\
& 1 Artisan (steel) & 1 Contract manager & $\mathbf{8}$ \\
Case Project 2: & 1 Project manager & 1 Technician \\
(Parking Garage) & 1 Director & & \\
& 1 Contract manager & & \\
& 1 Jnr Site agent & & $\mathbf{8}$ \\
& 1 Project administrator & 1 Principal technician & \\
Case Project 3: & 2 Jnr Quantity surveyors & 1 Contract manager & \\
(Refurbishment) & 1 Jnr Contract manager & & \\
& 1 Quantity surveyor & & $\mathbf{2 5}$ \\
\hline
\end{tabular}

The data analysis in case studies involves consolidating details about the case by examining, categorising, tabulating, and assembling the evidence to produce meaning. Yin (2013) mentioned that similarities across cases lead to replication of results in multiple case studies. Such replication provides the basis for compelling arguments. Also, Yin (2013) highlighted five analytical techniques for textual data analysis. These include pattern matching, explanation building, time series analysis, logic models, and cross-case synthesis. Cross-case analysis was suitable for this research since it involved data from interviews that were required to interpret the elements of each case. The textual data from the interview followed the open ended questions while the statistical data presented in the next section are descriptive to summarise the perspectives of the interviewees. Most of the interviewees agreed that LC is a process of eliminating waste, which can be implemented in South Africa (Table 2). They affirm their awareness of LC and other related concepts so there is a basis for their participation on the study. However, there level of engagement is limited as outlined in Emuze et al. (2017).

\section{RESULTS AND INTERPRETATIONS}

In Table 2, it is shown that, of the 25 interviewees, 23 (six from case project 1, nine from case project 2 and eight from case project 3 ) agreed that LC involves a continuous process of eliminating waste, meeting or exceeding all customer requirements, focusing on the entire value stream, and pursuing perfection in the execution of a construction project, while two disagreed with the statement. The responses showed that most of the interviewees were familiar with LC principles. As indicated in the table, 21 interviewees affirmed that they were aware of the possible impact that LC could have on South African construction. However, 18 of them indicated that, as contractors, they did not think LC could be implemented in South Africa. 
Table 2: Interviewees' Perceptions of Lean Construction Principles

\begin{tabular}{lccc}
\hline Questions & \multicolumn{3}{c}{ Interviewees' Responses } \\
\cline { 2 - 4 } & Yes & No & Unsure \\
Lean construction is continuous process of eliminating waste & $6+9+8$ & 2 & 0 \\
and meeting all customer requirements, and pursuing perfection & $(23)$ & & \\
on a project. & & & 1 \\
Awareness of the impact of lean construction in South Africa. & $6+9+6$ & $1+2(3)$ \\
As a contractor, do you think lean construction can be & $4+7+7$ & $2+2(4)$ & $2+1(3)$ \\
implemented in South Africa? & $(18)$ & & \\
\hline
\end{tabular}

In Table 3, it is shown that 21 interviewees perceived that there was resistance to LC in South Africa, while four of them disagreed. The lack of knowledge about LC among contractors was proposed as a major reason for the slow pace of adoption and four of the interviewees did not agree with the notion. However, most interviewees (23) agreed or strongly agree that leadership in organisations would play a major role in LC becoming mainstream in South Africa. The interviewees also concurred that adopting LC could help to reduce problems in South African construction. Thus, they believed that there should be increased awareness.

Table 3: Perceptions of Contractors' Attitude towards Lean Construction

\begin{tabular}{ccccc}
\hline Aspect & $\begin{array}{c}\text { Strongly } \\
\text { Disagree }\end{array}$ & $\begin{array}{c}\text { Disagree } \\
\text { There is resistance to change to LC in South Africa }\end{array}$ & 0 & $\begin{array}{c}\text { Agree } \\
\text { Strongly } \\
\text { Agree }\end{array}$ \\
\hline $\begin{array}{c}\text { Lack of LC knowledge is the reason why South African } \\
\text { construction is taking time to develop the system. }\end{array}$ & $0+1$ & $1+1$ & $5+6+5$ & $\begin{array}{c}1+2+2 \\
(5)\end{array}$ \\
Leadership plays a significant role in organisations & $(1)$ & $(3)$ & $(12)$ & $(9)$ \\
transforming to LC. & 0 & $1+1$ & $4+4+4$ & $3+4+2$ \\
Adopting a new system such as LC can help reduce & $0+1+1$ & $0+0+0$ & $3+3+6$ & $5+5+1$ \\
problems in South African construction. & $(2)$ & & $(12)$ & $(11)$ \\
There is a need to increase LC awareness in South & $0+0+0$ & $0+1+1$ & $1+4+2$ & $6+5+5$ \\
African construction. & & $(2)$ & $(7)$ & $(16)$ \\
\hline
\end{tabular}

\section{DATA RELATING TO ORGANISATIONAL CULTURE}

The first question put to the participants about organisational culture was whether South African contractors are set in their ways or would they be willing to change.

In Case Project 1, most participants responded positively that contractors would be willing to change their culture. They indicated "Yes", if the benefits of lean construction were to be made clear to all contractors, they would be willing to change. In Case Project 2, the majority responded "No", the organisations just needed to be exposed to better working conditions, such as LC, and firms would see the benefits. In Case Project 3, the majority responded "Yes", more information about LC and awareness would educate 
them more and, even though people were resisting change, with appropriate systems in place, people would adjust. The responses, as shown in Table 4, indicated that, while change towards LC is possible, the fixation on profit, low awareness of LC benefits, and unethical practices would slow down uptake of the approach. The creation of awareness by leaders in contracting firms, who also prioritise ethical ways of profit-making, should help to dismantle resistance to change. Knowing the dimensions that influence lean effectiveness and the way in which they exercise their influence, would enable company leaders to develop an organisational culture that would support the implementation of lean practices (Pakdil \& Leonard 2015).

Table 4: Responses Related to Change in Organisational Culture

\begin{tabular}{|c|c|}
\hline Case & Interview Responses \\
\hline \multirow[t]{2}{*}{$\begin{array}{c}\text { Case } \\
\text { Project } 1\end{array}$} & $\begin{array}{l}\text { - No, they are not and the unwillingness to change will derail the success the firms } \\
\text { envisage to achieve but they recognise change is inevitable. }\end{array}$ \\
\hline & $\begin{array}{l}\text { - Yes, they can change and some are willing because of the economy that is } \\
\text { against their company, lack of projects, being feared of company being } \\
\text { liquidated. } \\
\text { - If the benefits of lean construction were to be made clear to all, I believe they or } \\
\text { other contractors will change. }\end{array}$ \\
\hline \multirow{3}{*}{$\begin{array}{c}\text { Case } \\
\text { Project } 2\end{array}$} & - $\quad$ No, they are fearful to adopt new changes. \\
\hline & $\begin{array}{l}\text { - No, they just need to be exposed to better working conditions such as lean and } \\
\text { they will see the benefits. }\end{array}$ \\
\hline & $\begin{array}{l}\text { - Yes, they are somehow set in their ways; most contractors neglect quality of work } \\
\text { they deliver. }\end{array}$ \\
\hline \multirow{4}{*}{$\begin{array}{c}\text { Case } \\
\text { Project } 3\end{array}$} & - $\quad$ Yes, many are set but corruption plays a big role on projects. \\
\hline & $\begin{array}{l}\text { - Yes, more information on lean and awareness will educate them more about } \\
\text { lean. }\end{array}$ \\
\hline & $\begin{array}{l}\text { - Yes, even though people are resisting change but, with right systems in place, } \\
\text { people will adjust. }\end{array}$ \\
\hline & $\begin{array}{l}\text { - No, South African contractors' main focus on project is making money instead of } \\
\text { delivering to meet customer satisfaction. }\end{array}$ \\
\hline
\end{tabular}

The second question put to the participants about organisational culture was whether their company could operate at more profitable levels with their current leadership culture. Across the cases, the majority indicated "Yes", their company could operate at more profitably with the current leadership, while few participants indicated "No", change was needed in management and that there was not enough synergy within management.

The purpose of this question was to check whether a different leadership approach to management could make a difference in their performance. In Table 5, it is shown that few interviewees were in favour of an alternative leadership approach to managing their projects. There were only a few dissenters among them. The comments in Table 4 and 5 showed that there was scope for engaged and informed LC training among the firms involved in the case projects. 
Table 5: Responses to Organisational Culture Relating to Leadership Style

\begin{tabular}{cll}
\hline Case & & \multicolumn{1}{c}{ Interview Responses } \\
\hline Case & - & Yes, diversity and commitment to apply lean concept should be key. \\
Project 1 & - & Yes, in terms of tendering such as charging high from doing projects, but as for \\
& running the projects things are done smoothly. \\
Case & - & No, the leadership is fine. \\
Project 2 & - & Yes, fresh ideas bring new thinking. \\
& challenges currently facing management it is quite clear that a different option or \\
& choice can be tried. \\
& - Yes, there is always better way or different leadership approach to better what is \\
& currently done. \\
& No, we have great management team.
\end{tabular}

The third question about organisational culture asked the participants to indicate whether a different leadership approach to management could make a difference to company performance.

Relating to the practice of organisational culture, the responses in Table 6 indicated that the elements of LC were not addressed adequately. In Case Project 2, the project team admitted that the current leadership approach had to be utilised and, judging from the challenges currently facing management, it was quite clear that a different option should be tried. In Case Project 3, the team responded that the management and leadership were tools, so bringing in new ideas would lead the firm to greener pastures, as change towards improvement is always needed and LC would bring that. The responses in Case Project 1, where the majority believed that current leadership was fine, gave an opportunity to engage the team with LC philosophies, such as continuous improvement.

Table 6: Responses to Organisational Culture Relating to the Viability of LC

\begin{tabular}{cll}
\hline Case & & \multicolumn{1}{c}{ Interview Responses } \\
\hline $\begin{array}{c}\text { Case } \\
\text { Project 1 }\end{array}$ & - & Yes, can improve productivity and also save money. \\
& It can improve some sort of way maybe on financial side; company can get more money out \\
& of it.
\end{tabular}

The fourth question about organisational culture asked the interviewees whether lean thinking was a viable option for better performance and management change in their company. 
The participants had different views on LC being a viable option for better performance. In Case Project 1, the majority responded "Yes", LC could improve productivity, it could improve the financial in side some way, and the company could gain more money out of it. In Case Project 2, the interviewees responded "Yes", LC would be better for construction and the future development work of organisations. With the aim of decreasing time and waste of material, and increasing production, it would be necessary for LC to involve all parties in a project from design team to planning. In Case Project 3, the interviewees said "Yes", LC would ensure better management skills, which would improve the overall work environment in terms of material handling, staff participation and productivity. Also, workers would be exposed to training and would be better at what they were doing on site.

\section{CONCLUSIONS}

The question of how contractors could help drive the implementation of lean construction in South Africa was examined in the qualitative study reported in this paper. The findings of the study revealed that, although awareness of LC existed, contractors were resisting implementation. While some contractors believed that change was necessary and that LC promised great potential, there was dissent amongst the participants in the study sample. The interviewees were yet to come to the understanding that LC is based on a culture of respect and continuous improvement, aimed at creating value for the client by removing waste from the design and construction process (Seed 2017). As an illustration, the interviewed contractors can try to learn from DPR Construction. The form is an LC leader that attributed its success to its people and culture Maestas \& Parrish, 2014). In the firm, values and foundational principles are aligned to the positive change in the company.

It can be argued that the lack of projects demonstrating LC, the lack of hands-on experience of LC, and limited LC competencies among the contracting teams contributed substantially to their perspectives. The variance in views about LC might account for the inability of the project team-members interviewed to address the concepts in their organisations. Also, the interviewees had little knowledge of LC and its benefits according to the data.

Given that knowledge can be acquired through observation and study, it is essential to make LC education and training more accessible to practitioners through formal qualifications and continuous professional development (CPD) courses. Although researchers in tertiary education in South Africa are now producing treatises, dissertations and theses on LC from mainly two universities, the renewal of curriculum will add more strength to this endeavour. In a short time, availability of CPD courses could assist busy professionals such as the interviewees who indicated that their management have not tried LC in their performance improvement drive.

Thus, it was apparent that LC culture was lacking among contractors in the region. The challenge to implement LC lies in the establishment of an organisational culture that will enable the system to operate better in project-based, organisational settings. A step in the right direction to remedy the situation would be to use leadership, communication, empowerment, and teamwork (four elements) to effect change of culture in organisations. Doing so will support the use LC to create a common language and culture in contracting firms by providing an environment in which people with varying competencies and education can come together for a common good, which is about creating value for the client and society (Rubrich 2012). 
Further research would examine how the cultural framework, which is inclusive of the four elements mentioned, could be deployed in construction companies in South Africa.

\section{ACKNOWLEDGMENTS}

The authors would like to thank in advance all reviewers for their positive feedback on how to improve the paper. We would also like to thank the industry participants in the study.

\section{REFERENCES}

Ahmad, S.A.S. (2013). "Culture and lean manufacturing: Towards a holistic framework." Aust. J. Basic Appl. Sci., 7(1), 334-338.

AL-Najem, M., Dhakal, H. N. and Bennett, N. (2012)." The role of culture and leadership in lean transformation: A review and assessment model." International Journal of Lean Thinking, 3(1), 120-138.

Ballard, G. and Howell, G. (2003). "Lean project management." Building Research \& Information, 31(2), 119-133.

Creswell, J.W. (2013). "Qualitative inquiry \& research design: Choosing among five approaches (3rd ed.)." Thousand Oaks, CA: Sage.

Emuze, F., Masoga, T., and Sebetlele, C. (2017). "Lean Opportunity Assessment of Contractors' Supply Chain in South Africa.” In: LC3 2017 Volume II - Proceedings of the 25th Annual Conference of the International Group for Lean Construction (IGLC), Walsh, K., Sacks, R., Brilakis, I. (eds.), Heraklion, Crete, Greece pp. 797804. doi.org/10.24928/2017/0052.

Emuze, F. and Ungerer, H. (2014). "Change in South Africa Construction: Lessons from Lean Thinking." Proc., 22nd Annual Conf. of the International Group for Lean Construction, Oslo, Norway, pp. 1121-1131.

Fadnavis, S., Najarzadeh, A. and Badurdeen, F. (2020). "An assessment of organizational culture traits impacting problem solving for lean transformation." Procedia Manuf., 48, 31-42.

Forbes, L. H. and Ahmed, S. M. (2020). Modern construction: Lean project delivery and integrated practices. 2nd edition. Boca Raton: CRC Press.

Maestas, A. and Parrish, K. (2014). 'Exploring the Roots of Lean Culture at DPR Constuction - A Case Study in Lean culture' In:, Kalsaas, B. T., Koskela, L. \& Saurin, T. A., 22nd Annual Conference of the International Group for Lean Construction. Oslo, Norway, 25-27 Jun 2014. pp 1413-1424.

Pakdil, F. and Leonard, K. M. (2015). "The effect of organizational culture on implementing and sustaining lean processes." Journal of Manufacturing Technology Management, 26(5), 725-743.

Puvanasvaran, P., Tian, R. K.S. and Vasu, S.A. (2014). "Lean environmental management integration system for sustainability of ISO 14001:2004 standard implementation." Journal of Industrial Engineering and Management, 7(5), 11241144.

Rooke, J. (2020). People and knowledge: Lean organization. In: P. Tzortzopoulos, M. Kagioglou and L. Koskela eds. Lean construction: Core concepts and new frontiers. London: Routledge, pp. 85-101.

Rubrich, L. (2012). An introduction to Lean Construction: Applying lean to construction organizations and processes. Fort Wayne, IN: WCM Associates. 
Santorella, G. (2017). Lean culture for the construction industry: Building responsible and committed project teams. 2nd edition. Boca Raton, FL: Taylor \& Francis.

Sarhan, S. and Fox, A. (2013). "Barriers to implementing lean construction in the UK construction industry." The Built \& Human Environment Review, 6, 1-17.

Seed, R. (2017). Transforming design and construction. Arlington, VA: Lean Construction Institute.

Scoggin, J. C. (2017). The interdependency of lean implementation and organization development, PhD Thesis, Business Psychology, npp., nnp.

Tommelein, I.D. and Ballard, G. (2016). "Lean construction glossary". Berkeley: P2SL.

Van Rooyen, I. J. (2010). Lean construction. Should lean construction be part of a construction company's objective in South Africa. BSc (Hons) in Construction Management, University of Pretoria.

Yin, R. (2013). Qualitative research from start to finish. New York: The Guilford Press. 